\title{
Fundamental Reform of Payment for Adult Primary Care: Comprehensive Payment for Comprehensive Care
}

\author{
Allan H. Goroll, $M D^{7}$, Robert A. Berenson, $M D^{2}$, Stephen C. Schoenbaum, MD ${ }^{3}$, \\ and Laurence B. Gardner, $M D^{4}$
}

'Department of Medicine, Massachusetts General Hospital, Boston, Massachusetts 02114, USA; ${ }^{2}$ The Urban Institute, Washington, DC, USA;

${ }^{3}$ The Commonwealth Fund, New York, NY, USA; ${ }^{4}$ Department of Medicine, University of Miami School of Medicine, Miami, FL, USA.

Primary care is essential to the effective and efficient functioning of health care delivery systems, yet there is an impending crisis in the field due in part to a dysfunctional payment system. We present a fundamentally new model of payment for primary care, replacing encounter-based imbursement with comprehensive payment for comprehensive care. Unlike former iterations of primary care capitation (which simply bundled inadequate fee-for-service payments), our comprehensive payment model represents new investment in adult primary care, with substantial increases in payment over current levels. The comprehensive payment is directed to practices to include support for the modern systems and teams essential to the delivery of comprehensive, coordinated care. Income to primary physicians is increased commensurate with the high level of responsibility expected. To ensure optimal allocation of resources and the rewarding of desired outcomes, the comprehensive payment is needs/risk-adjusted and performance-based. Our model establishes a new social contract with the primary care community, substantially increasing payment in return for achieving important societal health system goals, including improved accessibility, quality, safety, and efficiency. Attainment of these goals should help offset and justify the costs of the investment. Field tests of this and other new models of payment for primary care are urgently needed.

KEY WORDS: primary care; comprehensive payment; capitation; resource-based relative value scale (RBRVS); compensation.

DOI: $10.1007 / \mathrm{s} 11606-006-0083-2$

๑) 2007 Society of General Internal Medicine 2007;22:410-415

\section{INTRODUCTION}

Ironically, at the very time definitive data are confirming primary care's essential contributions to health care (i.e., health status is improved and costs are reduced), ${ }^{1,2}$ adult primary care in the United States finds itself on the brink of crisis. ${ }^{3}$ Practicing primary care physicians are demoralized, retiring early, and advising others not to go into the field. ${ }^{3-5}$ The percentage of recent U.S. medical school graduates and residents planning to

Received August 24, 2006

Revised November 14, 2006

Accepted November 14, 2006

Published online January 9, 2007 enter primary care practice is plummeting to levels that will lead to serious physician shortages. ${ }^{6-11}$ The reasons for this decline are multifactorial, ${ }^{3-5,7,9,11-23}$ but a central factor has been a succession of dysfunctional payment systems that discourage proper delivery of primary care..$^{3-5,12,16-18,23-28}$ We propose a new payment model for primary care that realigns incentives and makes possible the establishment and operation of accountable, modern primary care practices capable of providing the personalized, coordinated, comprehensive care essential to a well-functioning health care system.

\section{FEATURES OF THE MODEL}

A risk/needs-adjusted comprehensive payment would be made to the primary care practice for the comprehensive care of each patient. It would replace all encounter-based payments made to the primary care physician under the resource-based relative-value scale (RBRVS) system. ${ }^{29}$ The payment would be directed to cover all practice expenses and salaries related to operating a robust, modern primary care practice (Table 1), one that would qualify as an "advanced medical home" for adults, a practice structure that enables efficient provision of comprehensive, coordinated, patient-centered care. ${ }^{30-32}$ Included would be monies for essential infrastructures and systems, most importantly, an interoperable electronic health record with decision support. ${ }^{33-37}$ Unlike primary care capitation systems, which also provided an aggregate payment (Table 2), ${ }^{38,39}$ our model's comprehensive payment would represent a net investment in primary care practices, not just the actuarially determined consolidation of inadequate RBRVS visit payments, as typically occurred under capitation. ${ }^{24,25,38,39}$ Total practice revenue would markedly increase compared to that under RBRVS; over two-thirds would be designated for the teams and systems essential to improving care (Table 1). Physician payment would also increase, commensurate with the responsibility assumed and value created (Table 3).

To encourage quality, safety, efficiency, and patient-centered care, we propose that a substantial proportion of the comprehensive payment (e.g., 15-25\%) be performance/outcomesbased and paid as a bonus for achieving valued outcomes. Determination of the performance bonus would require consensus goals and use of validated process and outcome measures agreed upon by payers and the profession (e.g., the Starter Set recommended by the National Committee on Quality Assurance). ${ }^{40}$

Both the comprehensive payment and the performance goals for the bonus would need to be risk- and needs-adjusted 
Table 1. Sample allocation formula for comprehensive payment system for adult primary care practice*

\begin{tabular}{l}
\hline \hline Formula for comprehensive payment for adult primary care \\
\hline $25 \%$ - Physician reimbursement: (250K before bonus and fringe) PCP \\
reimbursement (all care) \\
$60 \%$-Staff, fringe, rent, office expense (assumes hiring of \\
multidisciplinary office team charged with timely delivery of \\
personalized comprehensive care): (600K) \\
Nurse practitioner 100K \\
Nurse 90K \\
.5 FTE Nutritionist $35 \mathrm{~K}$ \\
$.5 \mathrm{FTE}$ Social worker $35 \mathrm{~K}$ \\
Receptionist $60 \mathrm{~K}$ \\
Medical assistant $50 \mathrm{~K}$ \\
Rent $40 \mathrm{~K}$ \\
Office expenses $50 \mathrm{~K}$ \\
Insurance $50 \mathrm{~K}$ \\
Physician fringe $75-90 \mathrm{~K}$ \\
$10 \%$-Information technology/patient safety/quality monitoring \\
(100K) \\
Purchase/lease/setup of electronic health record and quality \\
monitoring system $35 \mathrm{~K}$ \\
Data manager 65K \\
5\%-Performance bonus, annual meeting mutually established goals \\
(50k)
\end{tabular}

*Example assumes an average comprehensive payment of $\$ 500 / \mathrm{yr} / \mathrm{pt}$, an average panel size of 2,000 patients/full time primary care physician and team, 30\% fringe benefit unless otherwise specified, and gross revenue of $\$ 1.00 \mathrm{M} /$ full time equivalent primary care physician and team. Other models possible (see Table 2).

so as not to penalize practices for taking on the care of highrisk or psychosocially disadvantaged patients. The adjustments would depend on validated formulas, such as those using principal diagnoses in determining risk for ambulatory care $^{41-44}$ and those taking into account behaviors, psychosocial factors, and social environment to estimate need. ${ }^{45}$ These formulas would also allow for objective audit to ensure accuracy of the payment adjustment and discourage abuse. The expected manifold differences in actuarially determined care burdens would be reflected in correspondingly scaled payments; variation might be 10 -fold or more between the highest and lowest risk/needs categories.

Payment would be made monthly to help smooth cash flow and enable patients to conveniently change primary care practices. A monthly payment schedule would also underscore the shift from piece-work reimbursement to $24 / 7$ physician practice responsibility for patients. Patient copayments for primary care services could remain, but also might switch from per-visit payments to an actuarially determined costsharing component of the comprehensive payment, paid as part of the insurance premium.

The payment reform proposed requires concurrent practice transformation (i.e., establishment of the "advanced medical home") to achieve the necessary savings and improvements in care. Participation in the comprehensive payment system would be dependent on demonstration of the requisite structural and organizational changes. Organizations such as The National Committee for Quality Assurance are developing standards and measures for office practices ${ }^{46}$ that might be used to determine eligibility for the comprehensive payment. Participating practices would be expected to agree to periodic audit of standards such as these.

Payment for hospital and specialist services and ancillaries such as medications, laboratory tests, and imaging studies would remain the responsibility of payers and not the practices (unlike many prior iterations of primary care capitation, which placed primary care practices at unacceptable financial risk. $^{23-27}$ Minimizing under- and overutilization of such services can be achieved by 1) incorporating evidence-based guidelines for best practices into the practice's decisionsupport systems, ${ }^{33-36}$ and 2) by factoring into the pay-forperformance bonus calculation the attainment of consensus goals for cost-effectiveness, efficiency, health outcomes, and patient-centered care. Savings would be stimulated by encouraging best practices and achievement of validated cost-efficiency standards, but not by putting the practice at immediate financial risk for ordering specific tests on a particular patient or for the expenditures of other physicians and providers.

An adjustment to the comprehensive payment might need to be considered when some or all of the responsibility for comprehensive care is transferred to a specialist, as might occur in end-stage renal disease or cancer. Under such circumstances, the specialist might share in or receive the entire payment. Physicians with a specialty who wish to provide comprehensive primary care could participate in the new model if their practices meet advanced medical home standards. Such participating specialists who also perform unique procedural or other services that make a referral unnecessary might be paid an additional reduced fee-forservice payment under selected circumstances. Similarly, primary care physicians might be eligible for fee-for-service reimbursements for some services typically performed by specialists (e.g., skin biopsy).

Table 2. Comparison of Comprehensive Payment System with other Modes of Payment for Primary Care

\begin{tabular}{|c|c|c|c|c|c|c|}
\hline & $\begin{array}{c}\text { Comprehensive } \\
\text { primary } \\
\text { care payment }\end{array}$ & FFS & $\begin{array}{l}\text { FFS+ } \\
\text { P4P }\end{array}$ & Capitation & $\begin{array}{l}\text { Capitation + } \\
\text { P4P }\end{array}$ & $\begin{array}{c}\text { FFS + monthly } \\
\text { coordination fee }\end{array}$ \\
\hline Monthly payment includes all primary care services & + & - & - & + & + & - \\
\hline Payment for individual encounters & - & + & + & - & - & + \\
\hline Primary care practice at risk for services delivered by others & - & - & - & + (usually) & + & - \\
\hline Measurement of performance (technical and patient experience) & + & - & + & - & + & - \\
\hline Obligate probably reporting of performance & + & - & - & - & - & - \\
\hline Expect total costs of care to decrease & + & - & - & + & + & \pm \\
\hline Incentive to limit practice size & + & - & - & - & - & - \\
\hline Incentive to treat complex patients & + & - & - & - & - & + \\
\hline
\end{tabular}

FFS=fee for service

$\mathrm{PFP}=$ pay for performance 
Table 3. Examples of Possible Comprehensive Payments, Panel Sizes, and Allocations for Participating Adult Primary Care Practices*

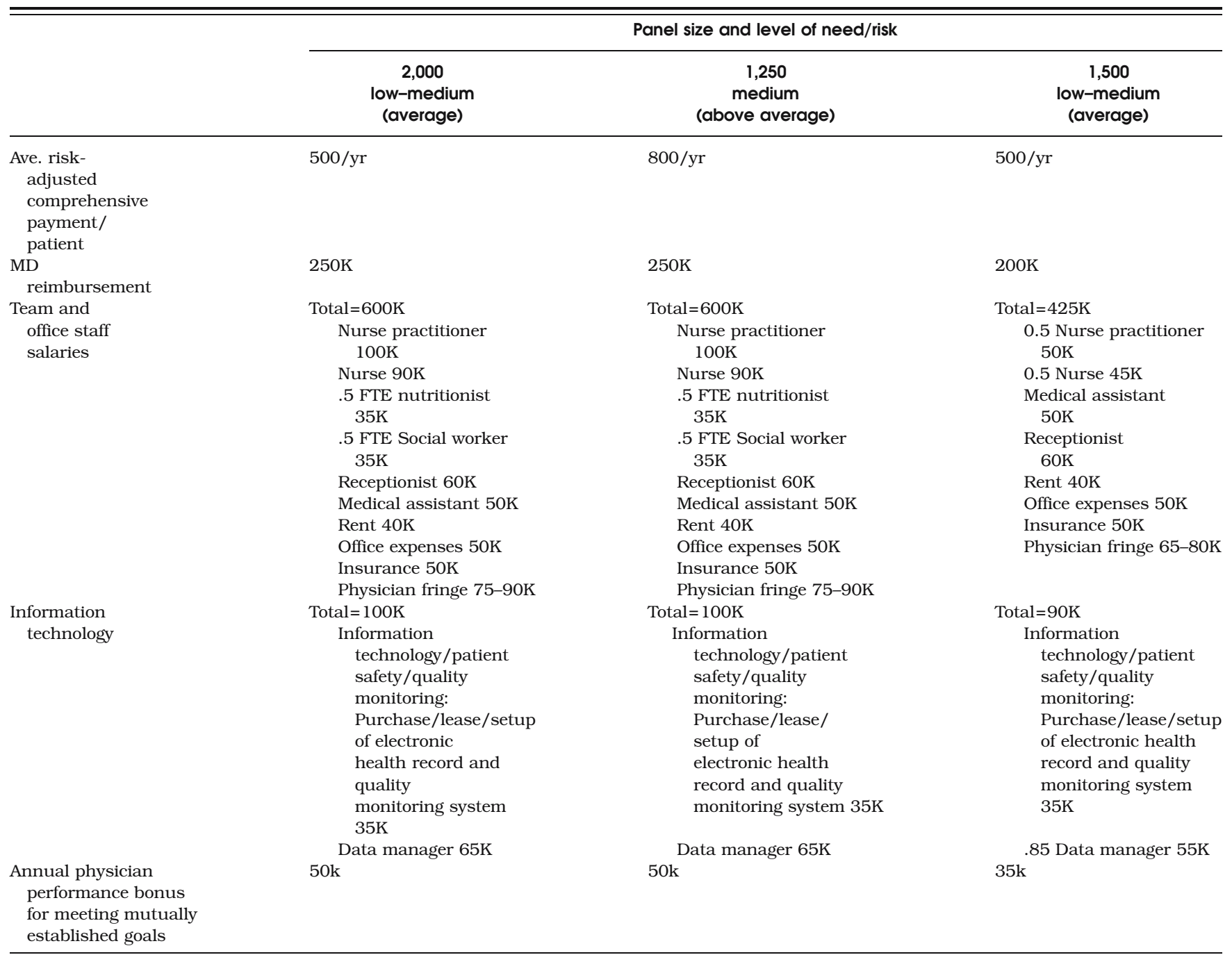

*The authors are not proposing a specific formula but rather putting forth the principle that it is possible to design many global compensation models that would provide adequate resources to ensure comprehensive, coordinated care to patients.

As alluded to earlier, installation and operation of an interoperable electronic health record (EHR) would be an essential requirement for practices desiring to participate in the comprehensive payment system, given the EHR's central role in transforming primary care practice ${ }^{30,33-37}$ and in facilitating auditing of care and outcomes. The costs of installation and operation of such a system are considered a legitimate and important component of the comprehensive payment (Table 1).

\section{TESTING AND IMPLEMENTING THE MODEL}

Pilot studies conducted in a variety of practice settings and involving a wide spectrum of patients will be needed to validate the proposed model. These investigations will require the collaborative efforts of the physician community, payers, purchasers, and patients, and should utilize an independent research group for data collection, monitoring, and analysis of clinical and economic outcomes. Medicare, as the largest payer and the one whose RBRVS system has been emulated by most other payers, should take the lead and, ideally, collaborate with other large payers to permit a true test of the new payment model.

Demonstration studies will need to address panel size, case mix, and levels of staffing, factors which affect the amount of time available and required for patient care activities (whether office visits, phone calls, record review, or team meetings), key determinants of patient and professional satisfaction. ${ }^{21,47} \mathrm{~A}$ range of panel sizes, cases mixes, payment levels, and staffing levels are possible (see Table 3). No single formula is likely to suffice for all settings and populations, but the common denominator needs to be adequate resources to support a comprehensive primary care effort.

There will be formidable research design issues, especially for controlled trials. The first studies might simply test feasibility. These would provide basic observational data comparing financial and patient outcomes pre and post change in reimbursement and relating those outcomes to the various practice models and patterns chosen by participating physicians.

Assuming that pilot studies of the model show promise, the subsequent challenge will be implementation. Most primary care practices do not have the necessary teams or systems in place; 
new monies will be needed to establish them. The proposed comprehensive payment makes available the financial resources for "tooling-up." Those primary care practices unsure of being able to make the transition directly to the comprehensive payment system might prefer more evolutionary steps (see below).

\section{STRENGTHS, WEAKNESSES, AND IMPLICATIONS}

This payment reform proposal represents an attempt to realign compensation with the primary care mission, providing comprehensive payment for comprehensive care. It frees practices from the growing inadequacy, irrationality, and administrative burdens of the existing RBRVS-based payment system, ${ }^{3,23,28,49-51}$ uncoupling primary care compensation from that of proceduralists, eliminating the zero-sum budgeting game, and overcoming the constraints of a payment system favoring procedure-based care. The model makes possible new payment rules better tailored to the primary care mission and more enabling of practice transformation. It has the potential to establish a new social contract, correcting chronic underpayment in return for accountability and achieving important health outcomes. It acknowledges in explicit financial terms the value primary care can create when properly organized and delivered, an obviously important factor in attracting new physicians to the field and stimulating practice transformation.

Proposing a comprehensive, aggregate payment is likely to evoke memories of primary care capitation with its pejorative connotations; however, there are important differences (Table 2), which lead us to avoid using the term "capitation" to describe our system. The most important differences are risk/ needs-adjustment, paying for performance to guard against underservice, and budgeting sufficient monies to support teams and infrastructures. These features are essential to avoiding the withholding of necessary care and the shunning of complex patients that too often occurred under the capitation initiatives of the past decade. ${ }^{25-27}$ In the new model, the gatekeeping of capitation is replaced by coordination and advocacy. Financial risk is borne predominantly by payers, who have the requisite actuarial and capital resources. Nonetheless, practices remain financially accountable, having to work within a global budget, adhere to professional standards of care and referral, and eliminate waste and inefficiency.

This model has some similarities and important differences with salaried models (Table 2). Like salaried models, there is no incentive to inflate the volume of face-to-face visits, but salaried models often have lacked the element of a social contract between the personal physician and the patient, supported in our model by a patient contribution to the retainer. In salaried environments, physicians tend to consider the organization as having the principal accountability to the patient; this has been reflected in lower patient trust of the individual physician. ${ }^{52-54}$

Risk adjustment is a key element of our payment model, both for determining the size of the aggregate monthly payment and for setting pay-for-performance goals. The first operational models of risk/needs adjustment (referred to as "case-mix adjustments") were diagnosis-based and validated for ambulatory care. ${ }^{55}$ Because primary care consists largely of ambulatory services, risk adjustment based on diagnoses is likely to be a reasonable approach to predicting the subsequent need for primary care services. Further iterations of risk adjustment by diagnosis have been operational for modifying payments at the health plan level ${ }^{56}$ and, if modified for application to the practice level, they should facilitate matching payment to care burden. Existing models based on diagnoses ${ }^{57-59}$ would seem a good fit for the payment system we have outlined. As noted earlier, a validated risk-adjustment framework that incorporates the full spectrum of important risk determinants, including those accounting for patient behaviors ${ }^{45}$ will be needed.

In a cost-conscious society, it is unlikely that the new payment model will be adopted widely if it is viewed as a giveaway to primary care physicians/practices. Conversely, primary care physicians are likely to reject the model if it appears to be yet another attempt to use them as gatekeepers or insurance companies. Our model tries to avoid both pitfalls by assigning most of the financial/actuarial risk to insurers while recognizing the responsibility of primary care practices to be financially and clinically accountable.

To put the financial challenge posed by the model in perspective, it is useful to consider the changes in total health spending that might result from implementation of our payment system and the savings that would be needed to offset them. Physician services currently constitute approximately $25 \%$ of all national spending for personal health services; of that amount, depending on the demographics of the population served, a quarter to a third constitutes payment for primary care services ${ }^{60}$. Thus, only $6-8 \%$ of total spending for personal health services currently represents payments to primary care physicians. If we propose a modest comprehensive payment schedule (e.g., an average of \$500 per patient per year; see Table 1), it would immediately increase total spending by $2-3 \%$, necessitating a $3 \%+$ reduction in the remaining $88-$ $90 \%$ of personal health care spending to offset the increase.

Current estimates of wasteful spending are as high as 30\% of total expenditures. ${ }^{61}$ Studies of electronic medical record systems with decision-support capacity (an essential feature of our payment/practice reform model) have demonstrated substantial savings from reductions in medical errors, pharmacy costs, adverse drug events, unnecessary radiology and laboratory utilization, and avoidable hospital admissions. ${ }^{33-36}$ Additional cost savings in care of the frail elderly are a reasonable expectation from improvements in coordination of care, ${ }^{30-32}$ particularly among the $30 \%$ of Medicare beneficiaries who have 4 or more chronic conditions and account for almost $80 \%$ of annual program spending. ${ }^{62}$ Even if our transformed primary care practices eventually achieve only a small fraction of the potential savings, that amount should offset the $2-3 \%$ projected increase in costs. Determining financial impact is a critical reason to test the model in pilot study.

In the short run, budget neutrality is unlikely and should not be expected, because upfront investments in practice reorganization and systems will take time to generate the expected savings. Nonetheless, the comprehensive payment model should provide readily apparent early benefits: First and foremost, patients (especially the elderly and the complexly ill) should notice improved access to care made possible by improvements in staffing, scheduling, and infrastructure (unlike concierge practices, which rely heavily on reducing panel size to improve access. ${ }^{63,64}$ With team practice freeing up the primary physician to perform more thorough patient evaluations, there should be less resorting to otherwise unnecessary tests and referrals. Other early benefits should 
include those mentioned earlier associated with implementation of the electronic health record. ${ }^{35-37}$ Rapid improvement in care is possible, as suggested by results in the first year of implementing an ambitious pay-for-performance bonus program for British general practitioners. ${ }^{65}$

Administrative burden has been a major criticism of the RBRVS system. ${ }^{28,49-51}$ Implementation of our model would eliminate claims billing and receiving as well as the onerous documentation and coding requirements associated with RBRVS, supplanting these purely administrative activities with more clinically relevant assessments of practice operations, patient panels, and clinical outcomes. By insisting on an electronic administrative/clinical infrastructure for practice participation in this payment reform, the model makes possible automated audits that should be less disruptive and lower in cost than the administrative demands of RBRVS. Despite the expected lessening of administrative burden, the benefits will not be realized until an electronic health record has been installed, which can be daunting for a small primary care practice, necessitating careful transition planning and budgeting for the changeover.

There is potential for abuses with this model, including misallocation of the comprehensive payment, gaming of the risk/needs-adjustment process, and "dumping" of care onto specialists. These require built-in countermeasures. Siphoning off payments targeted for team salaries and information infrastructure to enrich physician pay can be avoided by developing disbursement guidelines (e.g., Tables 1 and 3) and measures, which can be audited periodically. Use of validated objective measures of risk and need (e.g., principal diagnoses, ejection fraction, creatinine clearance, patterns of care utilization), and independent, random audits of the practice's electronic health record database should minimize chances of manipulating the risk-adjustment process. Dumping can be reduced by mandating sharing or outright transfer of the comprehensive payment when the specialist assumes most of the responsibility for care and by profiling the referral patterns of physicians, making payment adjustments where overreferrals are occurring. A payment that is adequately risk-adjusted is in itself a powerful disincentive to inappropriate transfer of patients to a specialist. Underutilization of referrals should be discouraged by the clinical outcomes and patient-experience components of our bonus payment determination.

An unintended consequence of this model's implementation might be practice downsizing. Practices that grew excessively large to meet expenses under fee for service might be tempted to "right-size" their panels to improve care and qualify for performance bonuses (see Table 2). If widely adopted, this could paradoxically reduce access for some ${ }^{64}$ and trigger a temporary shortage of primary care physicians. Alternatively, the expanded primary care team made possible by our model provides a means of devoting more attention to patients without the need to downsize (which can be painful for both patients and physicians). Moreover, by eliminating the disincentive to care for the complexly ill and needy, we are likely to improve access for those who need it most. With income independent of visit volume, smart delivery strategies (e.g., team care, interoperable medical records, email access, group visits, web-based patient education) can be implemented to reduce individual physician and team workloads, leaving more time for high-value face-to-face encounters, even home visits. Any shortage of primary care physicians that results from initial implementation of our model should be short-lived, as medical school graduates are attracted to the field by the promise of a financially secure, professionally satisfying career and practice environment.

Debate over implementation strategies will be vigorous. The potential for practice and system disruptions from payment reform cause some to argue for incremental approaches, such as increasing the valuation of RBRVS evaluation and management codes or adding a supplemental case management payment for care of high-risk patients. ${ }^{28,48}$ However, recent experience with capitation showed that if fee-for-service (e.g., under a modified form of RBRVS) continues, then even a comprehensive payment for some patients in a predominantly fee-for-service environment may not alter behavior; practices continue to reward "productivity" (as defined by number of patients seen and procedures performed) rather than develop other performance measures. ${ }^{66-68}$ Adding pay-for-performance to fee-for-service might help counter this behavior, but comprehensive pay for comprehensive care has the potential to be a more straightforward and effective approach to achieving the desired outcomes. Comparative studies are needed.

Primary care in the United States stands at a crossroads. We believe taking the road to recovery requires fundamental reform. It is urgent that new models of payment and practice be developed, tested, and implemented.

Potential Financial Conflicts of Interest: None disclosed.

Corresponding Author: Allan H. Goroll, MD; Department of Medicine, Massachusetts General Hospital, Boston, Massachusetts 02114, USA (e-mail: ahgoroll@partners.org).

\section{REFERENCES}

1. Starfield B, Shi L, Macinko J. Contribution of primary care to health systems and health. Milbank Q. 2005;83(3):457-502.

2. Ferrer RL, Hambridge SJ, Maly RC. The essential role of generalists in health care systems. Ann Intern Med. 2005;142:691-9.

3. American College of Physicians. The impending collapse of primary care medicine and its implications: in: the state of the nation's health care. A public policy report of the American College of Physicians, Philadelphia; January 30, 2006. Accessed at http://www.acponline.org/ hpp/statehc06.pdf. 11/5/06.

4. Sandy LG, Schroeder SA. Primary care in a new era: disillusion and dissolution? Ann Intern Med. 2003;138:262-7.

5. Moore G, Showstack J. Primary care medicine in crisis: towards reconstruction and renewal. Ann Intern Med. 2003;138:244-7.

6. Association of American Medical Colleges. Medical School Graduation Questionnaires, All Schools Reports 2006. http://www.aamc.org/data/ gq/allschoolsreports/2006.pdf. accessed 11/11/06.

7. Whitcomb ME, Cohen JJ. The future of primary care. N Engl J Med. 2004;351:710.

8. National Residency Matching Program: Positions offered in the matching program 1999-2005. accessed at http://www.nrmp.org/res_match/ tables/table1_05.pdf. Accessed 10/12/05

9. Silverman J. Match day reflects shift in IM training. Intern Med News. 2005;38:1 (April 1).

10. Signer MM, Beran RL. Results of the National Resident Matching Program for 2005. Acad Med. 2005;80:610-2.

11. Garibaldi RA, Popkave C, Bylsma W. Career plans for trainees in internal medicine residency programs. Acad Med. 2005;80:507-12.

12. Larson EB, the Society of General Internal Medicine (SGIM) Task Force on the Domain of General Internal Medicine. Health care system chaos should spur innovation: summary of a report of the Society of General Internal Medicine Task Force on the Domain of General Internal Medicine. Ann Intern Med. 2004;140:639-43. 
13. Lambert EM, Holmboe ES. The relationship between specialty choice and gender of U.S. medical graduates. Acad Med. 2005;80:797-802.

14. Blendon RJ, Schoen C, Donelan K, Osborn R, DesRoches CM, Scoles $\mathbf{K}$, et al. Physicians' views on quality of care: a five-country comparison. Health Aff (Millwood). 2001;20:233-43.

15. Mechanic D. Physician discontent: challenges and opportunities. JAMA 2003;290:941-6.

16. Kassirer JP. Doctor discontent. N Engl J Med. 1998;339:1543-5.

17. Grumbach K. Primary care in the United States-the best of times, the worst of times. N Engl J Med. 1999;341:2008-10. Editorial.

18. Showstack J, Lurie $\mathbf{N}$, Larson EB, et al. Primary care: the next renaissance. Ann Intern Med. 2003;138:268-72.

19. Institute of Medicine. Crossing the Quality Chasm: A New Health System for the 21 st Century. Committee on Quality of Health Care in America. Washington, DC: National Academy Press; 2001.

20. Ludmere, KM. Time to Heal. New York: Oxford University Press; 1999.

21. Safran DG. Defining the future of primary care: what can we learn from patients? Ann Intern Med. 2003;138:248-55.

22. Murphy J, Chang H, Montgomery JE, Rogers WH, Safran DG. The quality of physician-patient relationships. Patients' experiences 19961999. J Fam Pract. 2001;50:123-9.

23. Ginsburg PB. Payment and the future of primary care. Ann Intern Med. 2003;138:233-34. Editorial.

24. Grumbach K, Osmond D, Vranizan K, Jaffe D, Bindman AB. Primary care physicians' experience of financial incentives in managed-care systems. N Engl J Med. 1998;339:1516-21.

25. Goodson JD, Bierman AS, Fein O, Rask K, Rich EC, Selker HP. The future of capitation: the physician role in managing change in practice. $\mathrm{J}$ Gen Intern Med. 2001;16:250-6.

26. Bodenheimer T, Lo B, Casalino I. Primary care physicians should be coordinators, not gatekeepers. JAMA. 1999;281:2045-9.

27. Kassirer JP, Angel M. Risk adjustment or risk avoidance? N Engl J Med. 1998;339:1925-6.

28. American College of Physicians. Reform of a dysfunctional healthcare payment and delivery system. Philadelphia: American College of Physicians, 2006. Accessed at http://www.acponline.org/college/pressroom/ as06/dysfunctinoal_payment.pdf. 11/11/06.

29. Braun P, Hsiao WC, Becker ER, DeNicola M. Evaluation and manage ment services in the resource-based relative value scale. JAMA. 1988;260:2409-17.

30. American College of Physicians. The advanced medical home: a patient-centered physician-guided model of health care. Philadelphia: American College of Physicians. 2006. Accessed at http://www.acponline.org/hpp/adv_med.pdf. 11/11/06.

31. Wagner EH, Austin BT, Von Korff M. Organizing care for patients with chronic illness. Milbank Q. 1996;74:511-4.

32. Grumbach $\mathbf{K}$, Bodenheimer T. A primary care home for Americans: putting the house in order. JAMA. 2002;288:889-93.

33. Wang SJ, Middleton B, Prosser LA, Bardon CG, Spurr CD, Carchidi PJ, et al. A cost-benefit analysis of electronic medical records in primary care. Am J Med. 2003;114(5):397-403.

34. Hunt DL, Haynes RB, Hanna SE, Smith K. Effects of computer-based clinical decision support systems on physician performance and patient outcomes: a systematic review. JAMA. 1998;280:1339-46.

35. Chaudhry B, Wang J, Wu S, Maglione M, Mojica W, Roth E, et al Systematic review: impact of health information technology on quality, efficiency, and costs of medical care. Ann Intern Med. 2006;144:742-52.

36. Bates DW, Gawande AA. Improving safety with information technology. N Engl J Med. 2003;348:2526-34.

37. Delbanco T, Berwick DM, Boufford JI, Edgman-Sevitan S, Ollenschlager G, Plamping D, et al. Healthcare in a land called PeoplePower nothing about me without me. Health Expect. 2001;4:144-50.

38. Gold MR, Hurley R, Lake T, Ensor T, Berenson R. A national survey of the arrangements managed-care plans make with physicians. N Engl $\mathrm{J}$ Med. 1995;333:1678-83.

39. Kongstvedt PR. Compensation of primary care physicians in managed health care. In: Kongstvedt PR, ed. The Managed Health Care Handbook, 4th ed. Gaithersburg, Md.: Aspen Publishers; 2001.

40. AMA Physician Consortium on Performance Improvement, National Committee for Guality Assurance. Recommended Starter Set-Clinical Performance Measures for Ambulatory Care. Chicago: American Medical Association; 2005

41. Ash AS, Ellis RP, Pope GC, Ayanian JZ, Bates DW, Burstin H, et al. Using diagnoses to describe populations and predict costs. Health Care Financ Rev. 2000;21:7-28.
42. Newhouse JP, Buntin MD, Chapman JD. Risk adjustment and medicare: taking a closer look. Health Aff. 1997;16:26-43.

43. Kronick R, Gilmer T, Dreyfus T, Lee L. Improving health-based payment for Medicaid beneficiaries: CDPS. Health Care Financ Rev. 2000;21:29-64.

44. Iezzoni LI, ed. Risk Adjustment for Measuring Healthcare Outcomes; 3rd ed. Academy Health/HAP; 2003:508.

45. Rosen AK, Reid R, Broemeling A-M, Rakovski CC. Applying a riskadjustment framework to primary care: can we improve on existing measures? Ann Fam Med. 2003;1:44-51.

46. National Committee for Quality Assurance. Physician practice connection for Bridges to Excellence Program. Physician Office Link. Accessed at http://www.ncqa.org/draft/polindexdraft.htm. 11/11/06.

47. Wetterneck TB, Linzer M, McMurray JE, Douglas J, Schwarz, Bigby $\mathbf{J}$, et al. Worklife and satisfaction of general internists. Arch Intern Med. 2002;162:649-56.

48. Davis K, Schoenbaum SC, Audet A-M. A 2020 vision of patientcentered primary care. J Gen Intern Med. 2005;20:953-7.

49. Ginsburg PB, Grossman JM. When the price isn't right: how inadvertent payment incentives drive medical care. Health Affairs Web Exclusive, August 9, 2005. http://content.healthaffairs.org/cgi/reprint/hlthaff. w5.376v1? (Accessed 11/2/05).

50. MedPAC. Review of CMS's Preliminary Estimate of the Physician Update for 2006, Chapter 9 in Report to Congress: Issues in a Modernized Medicare Program. Washington, D.C. MedPAC, June 2005.

51. Brett AS. New guidelines for coding physicians' services: a step backward. N Engl J Med. 1998;23:1705-8.

52. Schoenbaum SC. Physicians and pre-paid group practices. Health Affairs web exclusive 2004;W4:76-78 (February 4, 2004). Accessible at http://content.healthaffairs.org/cgi/reprint/hlthaff.w4.76v1.pdf.

53. Safran DG, Wilson IB, Roger WH, Montgomery JE, Chang $\mathbf{H}$, et al. Primary care quality in the Medicare program: comparing the performance of Medicare Health Maintenance Organizations and traditional fee-for-service Medicare. Arch Intern Med. 2002;162:757-65.

54. Safran DG, Rogers WH, Tarlov AR, Inui T, Taira D, Montgomery JE, et al. Organizational and financial characteristics of health plans: are they related to primary care performance? Arch Intern Med. 2000;160:69-76.

55. Weiner JP, Starfield B, Steinwachs D, Mumford L. Development and application of a population-oriented measure of ambulatory care-mix. Med Care. 1991;29:452-72.

56. Weiner JP, Dobson A, Maxwell SL, Coleman K, Starfield B, Anderson GF. Risk-adjusted Medicare capitation rates using ambulatory and inpatient diagnoses. Health Care Financ Rev. 1996:77-99 (Spring).

57. Ash AS, Ellis RP, Pope GC, Ayanian JZ, Bates DW, Burstin H, et al. Using diagnoses to describe populations and predict costs. Health Care Financ Rev. 2000;21:7-28.

58. Newhouse JP, Buntin MD, Chapman JD. Risk adjustment and Medicare: taking a closer look. Health Aff. 1997;16:26-43.

59. Iezzoni LI, ed. Risk Adjustment for Measuring Healthcare Outcomes; 3rd ed. Academy Health/HAP;508pp; 2003.

60. Levit K, Smith C, Cowan C, Sensenig, A, Catlin, A. Trends: health spending rebound continues in 2002. Health Aff. 2004;24:147-59.

61. Fisher ES, Wennberg DS, Stukel TA, Gottlieb DJ, Lucas FL, Pinder EL. The implications of regional variations in Medicare spending, Parts 1 and 2. Ann Intern Med. 2003;138:273-98.

62. Berenson, RA, Horvath J. Confronting the Barriers to Chronic Care Management in Medicare," Health Affairs-Web Exclusive, Jan 22, 2003, accessible at http://content.healthaffairs.org/cgi/reprint/hlthaff.w3.37v1.

63. Zugar A. For a retainer, lavish care by 'boutique' doctors; in: 'Concierge medical service', waiting not part of health care experience. New York Times, October 30, 2005.

64. Brennan TA. Luxury primary care-market innovation or threat to access? N Engl J Med. 2002;346:1165-8.

65. Doran T, Fullwood C, Gravelle H, Reeves D, Kontopantelis E, Hiroeh U, et al. Pay-for-performance programs in family practices in the United Kingdom. N Engl J Med. 2006;355:375-84.

66. Conrad DA, Maynard C, Cheadle A, Ramsey S, Marchs-Smith M, Kirz H, et al. Primary care physician compensation method in medical groups: does it influence the use and cost of health services for enrollees in managed care organizations? JAMA. 1998;279:853-8.

67. Rosenthal, MB, Frank, RG, Buchanan, JL, Epstein AM. Transmission of financial incentives to physicians by intermediary organizations in California. Health Aff. 2002;21:197-205.

68. Robinson JC, Shortell SM, Li R, Casalino LP, Rundall T. The alignment and blending of payment incentives within physician organizations. Health Serv Res. 2004;39:1589-606. 